\title{
Usefulness of articulating laparoscopic instruments during laparoscopic gastrectomy for gastric adenocarcinoma
}

\author{
Eunju Lee ${ }^{1}$, Kanghaeng Lee ${ }^{1}$, So Hyun Kang ${ }^{1}$, Sangjun Lee ${ }^{1}$, Yongjoon Won ${ }^{1}$, Young Suk Park ${ }^{1,2}$, Sang-Hoon Ahn,2, \\ Yun-Suhk Suh ${ }^{1,2}$, Hyung-Ho Kim ${ }^{1,2}$ \\ ${ }^{1}$ Department of Surgery, Seoul National University Bundang Hospital, Seongnam, Korea \\ ${ }^{2}$ Department of Surgery, Seoul National University College of Medicine, Seoul, Korea
}

Purpose: Conventional straight-shaped laparoscopic surgical instruments have limitations that, unlike robotic surgery, the wrist joint cannot be used. This study aimed to analyze the short-term safety and feasibility of ArtiSential (Livsmed), a new articulating laparoscopic instrument, which obviates the limitations of conventional laparoscopic surgery and allows the wrist joint to be used freely over $360^{\circ}$ as in robotic surgery.

Methods: The study included patients who underwent conventional laparoscopy or laparoscopy with the ArtiSential instrument. Patients who underwent laparoscopic gastrectomy for primary gastric adenocarcinoma in our institution were retrospectively reviewed. The groups were propensity score matched in a 1:1 ratio. Primary endpoint was incidence of early postoperative complication (postoperative 30-day morbidity and mortality) and secondary endpoints were operative outcomes.

Results: A total of 327 patients (147 of the conventional group and 180 of the ArtiSential group) were propensity score matched. After propensity score matching was performed, each group comprised of 122 patients. Both groups were comparable with regard to operation time, estimated blood loss, number of retrieved lymph nodes, and length of hospital stay. The ArtiSential group had a faster time to a fluid diet (2.6 \pm 1.3 days vs. $2.3 \pm 0.6$ days, $p=0.015$ ). There was no statistically significant difference in early postoperative complications between the two groups (the conventional group, 23.0\%; the ArtiSential group, $26.2 \% ; p=0.656)$.

Conclusion: The current study showed that the use of ArtiSential is a safe and feasible option without increasing operation time, length of hospital stay, and intraoperative bleeding.

Keywords: Laparoscopy, Articulation, Stomach neoplasms, Gastrectomy

This is an Open Access article distributed under the terms of the Creative Commons Attribution Non-Commercial License (http:// creativecommons.org/licenses/by-nc/4.0/) which permits unrestricted non-commercial use, distribution, and reproduction in any medium, provided the original work is properly cited.
Received September 4, 2020

Revised 1st November 2, 2020 2nd November 12, 2020

Accepted November 13, 2020

Corresponding author

Sang-Hoon Ahn

Department of Surgery, Seoul

National University Bundang

Hospital, Seoul National University

College of Medicine, 82 Gumi-ro

173beon-gil, Bundang-gu, Seongnam 13620 , Korea

Tel: +82-31-787-7106

Fax: $+82-31-787-4078$

E-mail: viscaria@snubh.org

ORCID:

https://orcid.org/0000-0001-8827-3625

\section{INTRODUCTION}

The da Vinci robot, which has been actively used in recent years, has the advantage of being able to utilize three-dimensional (3D) images and wrist joints [1-4]. A surgeon using the robot can acquire a sense of depth through a 3D image, which is helpful for complex motions such as suturing anastomoses of the gastroin- testinal tract, based on simple motions such as grasping an item [5]. Further, the ability to use the wrist joint over $360^{\circ}$ during robotic surgery allows the surgeon a wide angle of motion, so that the accuracy of surgery is improved [6].

However, many studies have noted that patients have incurred notably higher costs for the advantages offered by robots $[7,8]$. Although each country has a different health insurance system, 
patients undergoing da Vinci robotic surgery will usually have to pay more than those undergoing laparoscopic surgery. Therefore, new methods utilizing the advantages of robots in laparoscopic surgery are emerging. The 3D cameras have already been used in clinical settings, and this institution conducted a prospective clinical trial to assess the benefits of these cameras [9].

Conventional straight-shaped laparoscopic surgical instruments have limitations, as they cannot use wrist joints unlike in robotic surgery. A new series of articulating laparoscopic instruments named ArtiSential (Livsmed, Seongnam, Korea) has been developed, and it obviates the limitations of conventional laparoscopic surgery and allows the wrist joint to be used freely over $360^{\circ}$ as in robotic surgery [10]. The device has been used in the clinical setting since May 2018 after approval by the Ministry of Food and Drug Safety of Korea and Health Insurance Review and Assessment Service of Korea. Because its usage in the clinical field is relatively new, there have only been few reports on its clinical usefulness [11-13]. The purpose of this study was to analyze the short-term safety and feasibility of ArtiSential in laparoscopic gastrectomy.

\section{MATERIALS AND METHODS}

Patients who underwent laparoscopic gastrectomy for primary gastric adenocarcinoma by a single surgeon from January 2017 to July 2019 at Seoul National University Bundang Hospital were retrospectively reviewed. Patients with a previous history of gastrectomy or those who underwent gastrectomy for palliative purposes were excluded. Since the introduction of ArtiSential in May 2018, the instrument has been used for all laparoscopic

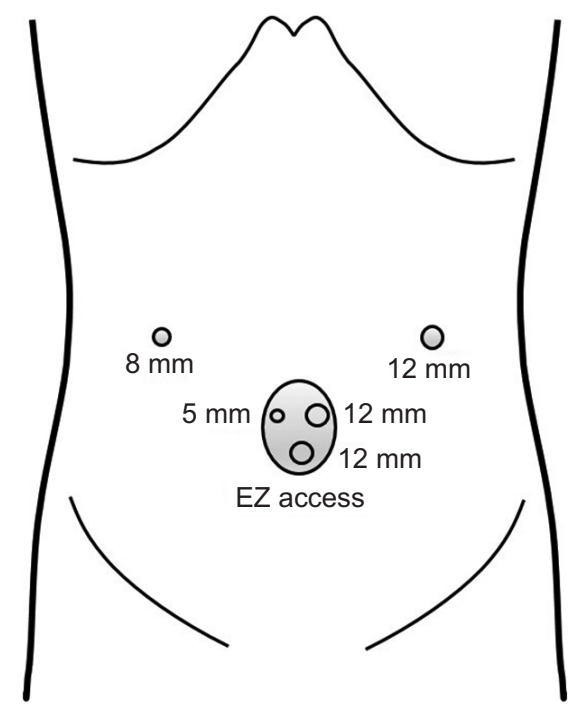

Fig. 1. Port placement for the conventional group and the ArtiSential group. ArtiSential: Livsmed, Seongnam, Korea; EZ Access: Hakko, Tokyo, Japan. gastrectomies in this institution. Patients were divided into two groups (conventional laparoscopy group and ArtiSential group); the conventional laparoscopic group was operated on from January 2017 to April 2018, and the ArtiSential group was operated on from May 2018 to July 2019. Baseline characteristics of the two groups were analyzed.

The primary endpoint was incidence of early postoperative complication (postoperative day [POD] 30 morbidity and mortality). Clavien-Dindo (CD) classification was used to evaluate the severity of postoperative complications [14]. Major complication was defined as CD complication grade IIIa or higher. Secondary outcomes were operative outcomes such as operation time, estimated blood loss (EBL), number of retrieved lymph nodes, length of hospital stay, white blood cell count and C-reactive protein level on POD 2, and decrease in hemoglobin after surgery. The decrease in hemoglobin was defined as the preoperative hemoglobin level minus the hemoglobin level at POD 2. These values were obtained from electronic medical records.

In laparoscopic gastrectomy, a 3D flexible scope was mainly used. After a transumbilical incision was made, ports were inserted. The number of ports varied depending on the operation. Usually, a Lap-Protector (Hakko, Tokyo, Japan) was inserted into the transumbilical wound and an EZ Access (Hakko, Tokyo, Japan) was connected. If necessary, additional ports were inserted into the right upper quadrant and left upper quadrant (Fig. 1). The use or nonuse of the articulating device did not influence the position of the laparoscopic port. Distal gastrectomy, proximal gastrectomy, pylorus-preserving gastrectomy, and total gastrectomy were performed for gastric cancer surgery. For distal gastrectomy, Billroth-I, Billroth-II, Roux-en-Y, or uncut Rouxen-Y anastomosis was performed. For proximal gastrectomy,

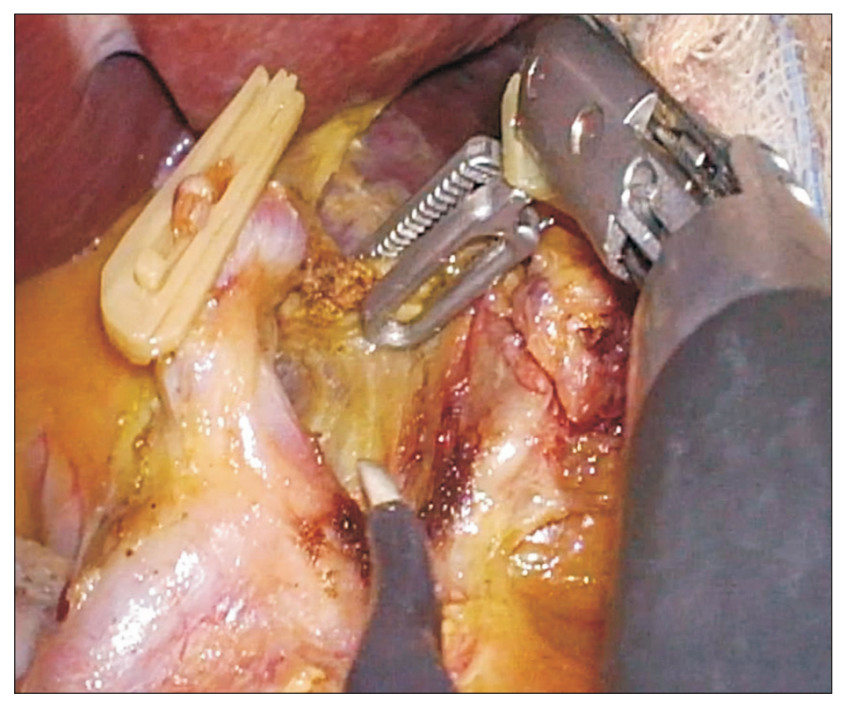

Fig. 2. No. 12 lymph node dissection using the fenestrated forceps (ArtiSential; Livsmed, Seongnam, Korea). 
Table 1. Baseline characteristics

\begin{tabular}{|c|c|c|c|c|c|c|}
\hline \multirow{2}{*}{ Characteristic } & \multicolumn{3}{|c|}{ All patients } & \multicolumn{3}{|c|}{ Propensity score matched patients } \\
\hline & Conventional group & ArtiSential group & $p$ value & Conventional group & ArtiSential group & $p$ value \\
\hline No. of patients & 147 & 180 & & 122 & 122 & \\
\hline Age (yr) & $61.1 \pm 12.1$ & $64.9 \pm 12.0$ & 0.006 & $62.4 \pm 12.1$ & $64.3 \pm 11.4$ & 0.214 \\
\hline Sex & & & 0.165 & & & 0.405 \\
\hline Male & $93(63.3)$ & $128(71.1)$ & & $81(66.4)$ & $88(72.1)$ & \\
\hline Female & $54(36.7)$ & $52(28.9)$ & & $41(33.6)$ & $34(27.9)$ & \\
\hline Body mass index (kg/m²) & $23.8 \pm 2.9$ & $24.1 \pm 3.6$ & 0.392 & $23.9 \pm 2.9$ & $24.3 \pm 3.5$ & 0.464 \\
\hline ASA PS classification & & & $<0.001$ & & & 0.646 \\
\hline I & $54(36.7)$ & $32(17.8)$ & & $33(27.0)$ & $29(23.8)$ & \\
\hline$\|$ & $82(55.8)$ & $119(66.1)$ & & $78(63.9)$ & $78(63.9)$ & \\
\hline ||| & $11(7.5)$ & $29(16.1)$ & & $11(9.0)$ & $15(12.3)$ & \\
\hline History of abdominal operations & & & 0.508 & & & 0.857 \\
\hline No & $125(85.0)$ & $147(81.7)$ & & $105(86.1)$ & $103(84.4)$ & \\
\hline Yes & $22(15.0)$ & 33 (18.3) & & $17(13.9)$ & $19(15.6)$ & \\
\hline Type of gastrectomy & & & 0.020 & & & 0.584 \\
\hline Distal & $107(72.8)$ & $115(63.9)$ & & $85(69.7)$ & $94(77.0)$ & \\
\hline Total & $19(12.9)$ & $33(18.3)$ & & $18(14.8)$ & $12(9.8)$ & \\
\hline Proximal & $2(1.4)$ & $14(7.8)$ & & $2(1.6)$ & $2(1.6)$ & \\
\hline Pylorus-preserving & $19(12.9)$ & $18(10.0)$ & & $17(13.9)$ & $14(11.5)$ & \\
\hline Lymph node dissection & & & 0.739 & & & 0.154 \\
\hline D1 & $7(4.8)$ & $7(3.9)$ & & $6(4.9)$ & $3(2.5)$ & \\
\hline D1+ & $54(36.7)$ & $57(31.7)$ & & $48(39.3)$ & $38(31.1)$ & \\
\hline D2 & $81(55.1)$ & $110(61.1)$ & & $63(51.6)$ & $79(64.8)$ & \\
\hline D2+ & $5(3.4)$ & $6(3.3)$ & & $5(4.1)$ & $2(1.6)$ & \\
\hline Resection of other organs & & & 0.982 & & & 0.848 \\
\hline No & $128(87.1)$ & $158(87.8)$ & & $106(86.9)$ & $107(87.7)$ & \\
\hline Yes & $19(12.9)$ & 22 (12.2) & & $16(13.1)$ & $15(12.3)$ & \\
\hline Size (cm) & $3.9 \pm 2.6$ & $4.2 \pm 2.9$ & 0.285 & $3.8 \pm 2.5$ & $3.7 \pm 2.3$ & 0.752 \\
\hline \multicolumn{7}{|l|}{ Resection margin (cm) } \\
\hline Proximal & $4.4 \pm 3.2$ & $3.4 \pm 2.6$ & 0.006 & $4.3 \pm 3.2$ & $3.7 \pm 2.5$ & 0.103 \\
\hline Distal & $5.2 \pm 3.7$ & $4.8 \pm 4.2$ & 0.381 & $5.0 \pm 3.6$ & $4.8 \pm 4.3$ & 0.681 \\
\hline T stage & & & 0.060 & & & 0.955 \\
\hline T1a & $48(32.7)$ & $56(31.1)$ & & $40(32.8)$ & $44(36.1)$ & \\
\hline$T 1 b$ & $41(27.9)$ & $56(31.1)$ & & $38(31.1)$ & $39(32.0)$ & \\
\hline T2 & $16(10.9)$ & $15(8.3)$ & & $12(9.8)$ & $12(9.8)$ & \\
\hline T3 & $30(20.4)$ & $22(12.2)$ & & $21(17.2)$ & $16(13.1)$ & \\
\hline $\mathrm{T} 4 \mathrm{a}$ & $8(5.4)$ & $26(14.4)$ & & $8(6.6)$ & $7(5.7)$ & \\
\hline $\mathrm{T} 4 \mathrm{~b}$ & $4(2.7)$ & $5(2.8)$ & & $3(2.5)$ & $4(3.3)$ & \\
\hline $\mathrm{N}$ stage & & & 0.462 & & & 0.788 \\
\hline NO & $93(63.3)$ & 114 (63.3) & & $76(62.3)$ & 83 (68.0) & \\
\hline N1 & $20(13.6)$ & 18 (10.0) & & $15(12.3)$ & $13(10.7)$ & \\
\hline N2 & $13(8.8)$ & $15(8.3)$ & & $13(10.7)$ & $14(11.5)$ & \\
\hline N3a & $16(10.9)$ & $19(10.6)$ & & $13(10.7)$ & $9(7.4)$ & \\
\hline N3b & $5(3.4)$ & $14(7.8)$ & & $5(4.1)$ & $3(2.5)$ & \\
\hline M stage & & & 0.838 & & & 0.478 \\
\hline 0 & $145(98.6)$ & $178(98.9)$ & & $120(98.4)$ & $122(100)$ & \\
\hline 1 & $2(1.4)$ & $2(1.1)$ & & $2(1.6)$ & $0(0)$ & \\
\hline
\end{tabular}

Values are presented as number only, mean \pm standard deviation, or number (\%).

ArtiSential: Livsmed, Seongnam, Korea. ASA PS, American Society of Anesthesiologists physical status. 
double tract reconstruction was mainly conducted [15], and in some cases, esophagogastrostomy with Toupet fundoplication or esophagogastrostomy with double flap reconstruction was performed. Among the ArtiSential graspers, bipolar fenestrated forceps were mostly used (Fig. 2). Supplementary Video 1 briefly illustrates how ArtiSential graspers can be used during laparoscopic gastrectomy. Generally, patients were discharged after eating soft blended diet, and without fever or other complications.

Propensity score matching (PSM) was used for demographic and clinicopathological variables to minimize bias that could occur between the two groups and to compensate for the shortcomings of the retrospective study. PSM was performed in a 1:1 ratio using age, sex, American Society of Anesthesiologists (ASA) classification [16], $\mathrm{T}$ stage, $\mathrm{N}$ stage, history of previous abdominal surgery, whether additional organs were excised during surgery, and type of gastrectomy as covariates. All statistical analyses were performed using $\mathrm{R}$ version 3.5.3 (R Foundation for Statistical Computing, Vienna, Austria). A $p$ value of $<0.05$ was determined to be statistically significant.

\section{RESULTS}

A total of 327 patients who underwent laparoscopic gastrectomy by a single surgeon from January 2017 to July 2019 were enrolled. Patients were divided into two groups; the conventional $(\mathrm{n}=$
147) and ArtiSential $(n=180)$ laparoscopy groups. Before PSM, there was a difference in baseline characteristics between the two groups (Table 1).

After PSM was performed, each group comprised 122 patients. The mean age was $62.4 \pm 12.1$ years in the conventional group and $64.3 \pm 11.4$ years in the ArtiSential group $(p=0.214)$. Patient characteristics such as sex, ASA score, type of operation, T stage, and $\mathrm{N}$ stage showed no significant differences between both groups after PSM (Table 1).

After PSM, the mean operation time was $163.6 \pm 69.4$ minutes in the conventional group and $165.2 \pm 55.0$ minutes in the ArtiSential group $(p=0.846)$. EBL was $46.7 \pm 103.6 \mathrm{~mL}$ in the conventional group and $28.1 \pm 40.8 \mathrm{~mL}$ in the ArtiSential group ( $p=$ 0.066 ). The number of retrieved lymph nodes was $59.7 \pm 21.7$ in the conventional group and $60.8 \pm 24.6$ in the ArtiSential group ( $p=0.722$ ). Patients had their first fluid diet an average of $2.6 \pm$ 1.3 days after surgery in the conventional group and $2.3 \pm 0.6$ days after surgery in the ArtiSential group $(p=0.015)$. The length of hospital stay was $6.1 \pm 3.2$ days in the conventional group and $6.8 \pm$ 3.5 days in the ArtiSential group $(p=0.117)$. Hemoglobin levels decreased by $1.2 \pm 1.7 \mathrm{~g} / \mathrm{dL}$ in the conventional group and by $1.3 \pm$ $1.2 \mathrm{~g} / \mathrm{dL}$ in the ArtiSential group ( $p=0.445$ ) (Table 2).

Early postoperative complications occurred in $23.0 \%$ of patients in the conventional group and in $26.2 \%$ of patients in the ArtiSential group; the difference was not statistically significant

Table 2. Operative outcomes

\begin{tabular}{|c|c|c|c|c|c|c|}
\hline \multirow[b]{2}{*}{ Outcome } & \multicolumn{3}{|c|}{ All patients } & \multicolumn{3}{|c|}{ Propensity score matched patients } \\
\hline & $\begin{array}{l}\text { Conventional group } \\
\quad(n=147)\end{array}$ & $\begin{array}{l}\text { ArtiSential group } \\
\quad(n=180)\end{array}$ & $p$ value & $\begin{array}{l}\text { Conventional group } \\
\quad(n=122)\end{array}$ & $\begin{array}{l}\text { ArtiSential group } \\
\quad(n=122)\end{array}$ & $p$ value \\
\hline Operation time (min) & $159.4 \pm 67.9$ & $182.1 \pm 135.9$ & 0.051 & $163.6 \pm 69.4$ & $165.2 \pm 55.0$ & 0.846 \\
\hline $\mathrm{EBL}(\mathrm{mL})$ & $46.1 \pm 97.5$ & $33.3 \pm 49.5$ & 0.150 & $46.7 \pm 103.6$ & $28.1 \pm 40.8$ & 0.066 \\
\hline Intraoperative transfusion & & & 0.919 & & & 0.316 \\
\hline No & $146(99.3)$ & $180(100)$ & & $121(99.2)$ & $122(100)$ & \\
\hline Yes & $1(0.7)$ & $0(0)$ & & $1(0.8)$ & $0(0)$ & \\
\hline Retrieved LN (n) & $59.6 \pm 21.5$ & $60.8 \pm 24.9$ & 0.652 & $59.7 \pm 21.7$ & $60.8 \pm 24.6$ & 0.722 \\
\hline Positive LN (n) & $2.4 \pm 6.1$ & $4.3 \pm 11.0$ & 0.049 & $2.6 \pm 6.5$ & $2.6 \pm 9.9$ & 0.960 \\
\hline First fluid diet (day) & $2.5 \pm 1.2$ & $2.5 \pm 0.9$ & 0.656 & $2.6 \pm 1.3$ & $2.3 \pm 0.6$ & 0.015 \\
\hline Length of hospital stay (day) & $6.0 \pm 3.1$ & $7.7 \pm 7.5$ & 0.005 & $6.1 \pm 3.2$ & $6.8 \pm 3.5$ & 0.117 \\
\hline 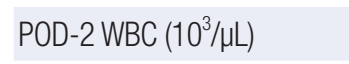 & $11.1 \pm 3.8$ & $10.8 \pm 3.2$ & 0.437 & $11.1 \pm 4.0$ & $11.1 \pm 3.1$ & 0.980 \\
\hline POD-2 CRP (mg/dL) & $12.3 \pm 6.3$ & $12.9 \pm 5.5$ & 0.329 & $12.7 \pm 6.4$ & $13.1 \pm 5.5$ & 0.618 \\
\hline Decrease in $\mathrm{Hb}^{\mathrm{a})}(\mathrm{g} / \mathrm{dL})$ & $1.2 \pm 1.6$ & $1.2 \pm 1.2$ & 0.731 & $1.2 \pm 1.7$ & $1.3 \pm 1.2$ & 0.445 \\
\hline
\end{tabular}

Values are presented as mean \pm standard deviation or number (\%).

ArtiSential: Livsmed, Seongnam, Korea. EBL, estimated blood loss; LNs, lymph nodes; POD, postoperative day; WBC, white blood cell; CRP, C-reactive protein; $\mathrm{Hb}$, hemoglobin.

a)Preoperative Hb - POD-2 Hb. 
Table 3. Early postoperative complications

\begin{tabular}{|c|c|c|c|c|c|c|}
\hline \multirow[b]{2}{*}{ Variable } & \multicolumn{3}{|c|}{ All patients } & \multicolumn{3}{|c|}{ Propensity score matched patients } \\
\hline & $\begin{array}{l}\text { Conventional group } \\
\qquad(n=147)\end{array}$ & $\begin{array}{l}\text { ArtiSential group } \\
\quad(n=180)\end{array}$ & $p$ value & $\begin{array}{l}\text { Conventional group } \\
\qquad(\mathrm{n}=122)\end{array}$ & $\begin{array}{l}\text { ArtiSential group } \\
\quad(n=122)\end{array}$ & $p$ value \\
\hline Early complication event (SPOD 30) & & & 0.395 & & & 0.656 \\
\hline No & $117(79.6)$ & $135(75)$ & & $94(77.0)$ & $90(73.8)$ & \\
\hline Yes & $30(20.4)$ & $45(25)$ & & $28(23.0)$ & $32(26.2)$ & \\
\hline \multicolumn{7}{|l|}{ Details of complication } \\
\hline Cardiac morbidity & $1(3.1)$ & $2(3.8)$ & & $1(3.2)$ & $2(5.0)$ & \\
\hline Pulmonary morbidity & $19(59.4)$ & $24(45.3)$ & & $19(61.3)$ & $17(42.5)$ & \\
\hline Urinary morbidity & $0(0)$ & $0(0)$ & & $0(0)$ & $0(0)$ & \\
\hline Intra-abdominal abscess & $2(6.3)$ & $5(9.4)$ & & $2(6.5)$ & $5(12.5)$ & \\
\hline Anastomotic leakage & $2(6.3)$ & $5(9.4)$ & & $2(6.5)$ & $2(5.0)$ & \\
\hline Stump leakage & $0(0)$ & $0(0)$ & & $0(0)$ & $0(0)$ & \\
\hline Anastomotic bleeding & $1(3.1)$ & $2(3.8)$ & & $1(3.2)$ & $2(5.0)$ & \\
\hline Intestinal obstruction & $4(12.5)$ & $7(13.2)$ & & $3(9.7)$ & $5(12.5)$ & \\
\hline Pancreatic fistula & $0(0)$ & $0(0)$ & & $0(0)$ & $0(0)$ & \\
\hline Postoperative pancreatitis & $2(6.3)$ & $0(0)$ & & $2(6.5)$ & $0(0)$ & \\
\hline Wound morbidity & $0(0)$ & $2(3.8)$ & & $0(0)$ & $2(5.0)$ & \\
\hline Other early complications ${ }^{\mathrm{b}}$ & $1(3.1)$ & $6(11.3)$ & & 1 (3.2) & $5(12.5)$ & \\
\hline Early complication, $\geq \mathrm{CD}$ grade Illa & & & 0.095 & & & 0.438 \\
\hline No & $141(95.9)$ & $163(90.6)$ & & $116(95.1)$ & $112(91.8)$ & \\
\hline Yes & $6(4.1)$ & $17(9.4)$ & & $6(4.9)$ & $10(8.2)$ & \\
\hline Early complications (CD grade) & & & 0.465 & & & 0.840 \\
\hline I & $12(8.2)$ & $12(6.7)$ & & $11(9.0)$ & $9(7.4)$ & \\
\hline$\|$ & $12(8.2)$ & $16(8.9)$ & & $11(9.0)$ & $13(10.7)$ & \\
\hline Illa & $4(2.7)$ & $6(3.3)$ & & $4(3.3)$ & $4(3.3)$ & \\
\hline IIllb & $0(0)$ & $3(1.7)$ & & $0(0)$ & $1(0.8)$ & \\
\hline $\mathrm{IVa}$ & $1(0.7)$ & $5(2.8)$ & & $1(0.8)$ & $3(2.5)$ & \\
\hline $\mathrm{IVb}$ & $0(0)$ & $2(1.1)$ & & $0(0)$ & $1(0.8)$ & \\
\hline V & $1(0.7)$ & $1(0.6)$ & & $1(0.8)$ & $1(0.8)$ & \\
\hline
\end{tabular}

Values are presented as number (\%).

ArtiSential: Livsmed, Seongnam, Korea. POD, postoperative day; CD, Clavien-Dindo classification.

${ }^{a}$ The denominator was calculated as the number of patients with complication in each group. ${ }^{b}$ Includes acute cholecystitis, colitis, and fever of unknown origin.

( $p=0.656)$. Major complications (CD IIIa or higher) occurred in six patients (4.9\%) in the conventional group and in 10 patients (8.2\%) in the ArtiSential group; the difference was also not statistically significant $(p=0.438)$ (Table 3).

In the conventional group, two patients had a percutaneous drain insertion for anastomosis leakage (CD grade IIIa), two patients had percutaneous drain insertion for fluid collection (CD grade IIIa), and one patient was treated in the intensive care unit (ICU) due to pulmonary complications (CD grade IVa). In the conventional group, one mortality was recorded. The patient was a 54-year-old man with a history of hypertension, diabetes, and ischemic heart disease with coronary intervention. He underwent laparoscopic distal gastrectomy and died due to myocardial infarction on the operation day. 


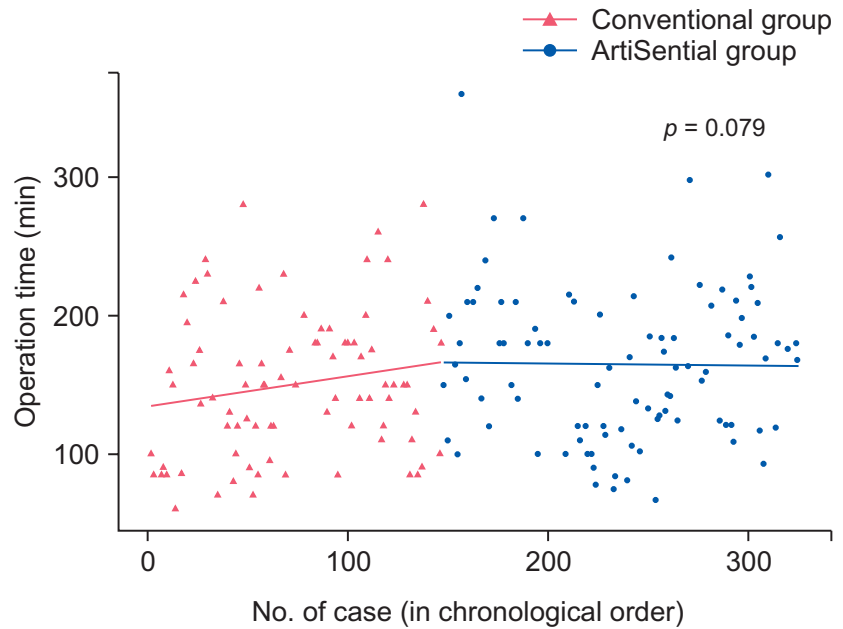

Fig. 3. Operation time of laparoscopic distal gastrectomy in chronological order. ArtiSential: Livsmed, Seongnam, Korea.

In the ArtiSential group, one patient underwent reoperation and was treated in the ICU and one patient received percutaneous drain insertion for anastomosis leakage (CD grade IVa and $\mathrm{CD}$ grade IIIa, respectively). Three patients underwent percutaneous drain insertion for fluid collection (CD grade IIIa) and two patients had endoscopic hemostasis due to anastomosis bleeding and were treated in the ICU (CD grade IVa). One patient underwent thoracentesis for pleural effusion (CD grade IIIa) and one patient had new-onset atrial fibrillation and was treated in the ICU (CD grade IVa). One patient received a percutaneous transhepatic gallbladder drain for acute cholecystitis (CD grade IIIa). In the ArtiSential group, one mortality was recorded. The patient was an 83-year-old woman with a history of hypertension, diabetes, dyslipidemia, and dilated cardiomyopathy. She underwent laparoscopic distal gastrectomy and died due to cardiac arrest on POD 9.

\section{DISCUSSION}

In this study, there was no significant difference in the occurrence of early postoperative complications between the conventional and ArtiSential groups. The use of the novel articulating device was feasible and did not increase short-term operative complications. To the best of our knowledge, no study has reported the comparison of operation outcomes and complications of laparoscopic gastrectomy using ArtiSential and robotic gastrectomy. In previous studies, when robotic gastrectomy and conventional laparoscopic gastrectomy for gastric adenocarcinoma were compared, postoperative complications were similar with robotic gastrectomy [7,17-19]. Thus, a study comparing robotic surgery versus laparoscopic surgery using the new articulating device is needed. According to the 2016 International Study Group on Pancreatic Fistula (ISGPF), postoperative pancreatic fistula (POPF) is defined as a drain output of any quantifiable volume of fluid with an amylase level more than three times the upper limit of institutional normal serum amylase value, related with a clinically relevant development/condition associated directly to the POPF [20]. When there was no intraoperative event, the participating surgeon in this study did not insert surgical drains in accordance with the early recovery after surgery program. Hence, it was difficult to define POPF according to 2016 ISGPF definition [20]. In this study, POPF could be clinically diagnosed when fluid collection near the pancreas was found in computed tomography scans after fever or abdominal pain. Consequently, POPF and postoperative pancreatitis might have been underestimated compared to other studies.

There was no significant difference in operative outcomes, such as operation time, between the conventional and ArtiSential groups. Fig. 3 shows the time of operation for laparoscopic distal gastrectomy in chronological order. Before the first patient in the study, the operator had already performed more than 1,000 cases of laparoscopic gastrectomy, so the learning curve for laparoscopic gastrectomy had already been passed before the beginning of the study. Nevertheless, ArtiSential is a new device and a learning curve cannot be avoided when a new surgical instrument is introduced. Even if the surgeon practices sufficiently in the dry lab, the operation time would be longer during actual surgery until the learning curve is overcome. A learning curve still existed with the ArtiSential group, but there was no significant difference in operation time between the two groups. As the dissection can be performed freely using the wrist joint over $360^{\circ}$, it takes less time compared to a conventional straight device. Moreover, ArtiSential is able to perform motions that are not possible with conventional straight laparoscopic instruments, especially intracorporeal suturing, with a notably larger degree of freedom. For these reasons, there seemed to be no difference in the overall operation time. A study focusing on the time it takes to overcome the learning curve when using ArtiSential is currently ongoing.

The use of ArtiSential does not increase blood loss and may be beneficial in reducing EBL. There was a difference of $18 \mathrm{~mL}$ in EBL between the two groups, with the ArtiSential group having less blood loss. Although the difference in blood loss is small, and may not be clinically significant, this may be due to the use of bipolar electrocautery function of the ArtiSential. The addition of bipolar energy to these graspers is effective for bleeding control. This also allows the use of the "double bipolar technique" [21] in lymph node dissection, previously possible only in robotic surgery, in laparoscopic surgery. During lymph node dissection, ArtiSential enables fine dissection that reduces the possibility of thermal damage to the surrounding normal tissues. In particular, thermal injury to the pancreas is reduced during suprapancreatic 
lymph node dissection. The time to start a fluid diet was 0.3 days faster in the ArtiSential group, and, although statistically significant, further research is needed to verify if this is of notable clinical value.

An important limitation of this study is its retrospective design. Since ArtiSential was used from May 2018, there is a time bias that cannot be excluded because of the retrospective nature of the study. However, this study was designed to assess the feasibility of the new device through short-term safety, targeting the non-inferiority of the new intervention. Hence, this time bias does not change the conclusion regarding the feasibility of the device. Subsequent prospective randomized controlled trials will be needed to validate if this new articulating device has advantages over current conventional laparoscopic surgery or robotic surgery. Other limitations of this study include its singlecenter nature and the performance of the procedures by a single surgeon; further prospective studies involving more surgeons are needed. In addition, bias reduction was attempted through PSM, resulting in a smaller number of patients compared to the initial sample size. As such, future studies with a larger number of patients may be necessary. Lastly, this study focused on early postoperative morbidity and mortality, so research with longerterm follow-up data is needed to analyze the long-term safety of the device.

In conclusion, the new laparoscopic articulating device, ArtiSential, is a safe and feasible option that does not increase operation time, length of hospital stay, and intraoperative bleeding. Nevertheless, a well-designed prospective study of the safety and feasibility of ArtiSential is needed.

\section{NOTES}

\section{Ethical statements}

The study was commenced after the approval of the institutional review board of Seoul National University Bundang Hospital (B1909-565-102), and was in accordance with the Helsinki declaration. Informed consent was obtained from all patients after a thorough verbal explanation.

\section{Authors' contributions}

Conceptualization: YSP, SHA, YSS, HHK

Data curation: EL, KL, SHK

Formal analysis: EL, SHK

Funding acquisition: SHA

Investigation: EL, SHK

Methodology: SL, YW

Project administration: SHA

Visualization: EL, SHK
Writing-original draft: EL

Writing-review \& editing: All authors

All authors read and approved the final manuscript.

\section{Conflict of interest}

All authors have no conflicts of interest to declare.

\section{Funding/support}

This work was supported by 'Supporting Project to Evaluate New Domestic Medical Devices in Hospitals' funded by Ministry of Health and Welfare (MOHW) and Korea Health Industry Development Institute (KHIDI) (No. 08-2020-098).

\section{ORCID}

Eunju Lee, https://orcid.org/0000-0003-2168-6534

Kanghaeng Lee, https://orcid.org/0000-0003-0241-2781

So Hyun Kang, https://orcid.org/0000-0002-8248-9043

Sangjun Lee, https://orcid.org/0000-0001-9498-0254

Yongjoon Won, https://orcid.org/0000-0001-9222-288X

Young Suk Park, https://orcid.org/0000-0002-6352-9759

Sang-Hoon Ahn, https://orcid.org/0000-0001-8827-3625

Yun-Suhk Suh, https://orcid.org/0000-0003-3319-8482

Hyung-Ho Kim, https://orcid.org/0000-0002-8916-0048

\section{Supplementary materials}

Supplementary materials can be found via https://doi.org/10.7602/ jmis.2021.24.1.35.

\section{REFERENCES}

1. Lanfranco AR, Castellanos AE, Desai JP, Meyers WC. Robotic surgery: a current perspective. Ann Surg 2004;239:14-21.

2. Byrn JC, Schluender S, Divino CM, et al. Three-dimensional imaging improves surgical performance for both novice and experienced operators using the da Vinci Robot System. Am J Surg 2007;193:519522.

3. Hanly EJ, Talamini MA. Robotic abdominal surgery. Am J Surg 2004; 188(4A Suppl):19S-26S.

4. Gutt CN, Oniu T, Mehrabi A, Kashfi A, Schemmer P, Büchler MW. Robot-assisted abdominal surgery. Br J Surg 2004;91:1390-1397.

5. Jayaraman S, Quan D, Al-Ghamdi I, El-Deen F, Schlachta CM. Does robotic assistance improve efficiency in performing complex minimally invasive surgical procedures? Surg Endosc 2010;24:584-588.

6. Chitwood WR Jr, Nifong LW, Chapman WH, et al. Robotic surgical training in an academic institution. Ann Surg 2001;234:475-484.

7. Kim HI, Han SU, Yang HK, et al. Multicenter prospective compara- 
tive study of robotic versus laparoscopic gastrectomy for gastric adenocarcinoma. Ann Surg 2016;263:103-109.

8. Close A, Robertson C, Rushton S, et al. Comparative cost-effectiveness of robot-assisted and standard laparoscopic prostatectomy as alternatives to open radical prostatectomy for treatment of men with localised prostate cancer: a health technology assessment from the perspective of the UK National Health Service. Eur Urol 2013;64:361369.

9. Lee K, Youn SI, Won Y, et al. Prospective randomized controlled study for comparison of 2-dimensional versus 3-dimensional laparoscopic distal gastrectomy for gastric adenocarcinoma. Surg Endosc 2021;35:934-940.

10. Min SH, Cho YS, Park K, et al. Multi-DOF (degree of freedom) articulating laparoscopic instrument is an effective device in performing challenging sutures. J Minim Invasive Surg 2019;22:157-163.

11. Kang SH, Cho YS, Min SH, et al. Intracorporeal overlap gastrogastrostomy for solo single-incision pylorus-preserving gastrectomy in early gastric cancer. Surg Today 2019;49:1074-1079.

12. Kim YY, Lee Y, Lee CM, Park S. Lymphadenectomy using two instrument arms during robotic surgery for gastric cancer: a strategy to facilitate reduced-port robotic gastrectomy. Asian J Surg 2020;43:459466.

13. Jin HY, Lee CS, Lee YS. Laparoscopic extended right hemicolectomy with D3 lymph node dissection using a new articulating instrument. Tech Coloproctol 2020 Sep 14 [Epub]. https://doi.org/10.1007/s10151020-02345-Z.
14. Clavien PA, Barkun J, de Oliveira ML, et al. The Clavien-Dindo classification of surgical complications: five-year experience. Ann Surg 2009;250:187-196.

15. Ahn SH, Jung DH, Son SY, Lee CM, Park DJ, Kim HH. Laparoscopic double-tract proximal gastrectomy for proximal early gastric cancer. Gastric Cancer 2014;17:562-570.

16. Keats AS. The ASA classification of physical status: a recapitulation. Anesthesiology 1978;49:233-236.

17. Woo Y, Hyung WJ, Pak KH, et al. Robotic gastrectomy as an oncologically sound alternative to laparoscopic resections for the treatment of early-stage gastric cancers. Arch Surg 2011;146:1086-1092.

18. Hyun $\mathrm{MH}$, Lee $\mathrm{CH}$, Kwon YJ, et al. Robot versus laparoscopic gastrectomy for cancer by an experienced surgeon: comparisons of surgery, complications, and surgical stress. Ann Surg Oncol 2013;20: 1258-1265.

19. Han DS, Suh YS, Ahn HS, et al. Comparison of surgical outcomes of robot-assisted and laparoscopy-assisted pylorus-preserving gastrectomy for gastric cancer: a propensity score matching analysis. Ann Surg Oncol 2015;22:2323-2328.

20. Bassi C, Marchegiani G, Dervenis C, et al. The 2016 update of the International Study Group (ISGPS) definition and grading of postoperative pancreatic fistula: 11 years after. Surgery 2017;161:584-591.

21. Uyama I, Kanaya S, Ishida Y, Inaba K, Suda K, Satoh S. Novel integrated robotic approach for suprapancreatic D2 nodal dissection for treating gastric cancer: technique and initial experience. World J Surg 2012;36:331-337. 